\title{
A review on the pharmagnostic evaluation of Meswak, Salvadora persica
}

\author{
Deepak Kumar Sharma, ${ }^{1 *}$ K. R. Shah ${ }^{2}$ and R. S. Dave ${ }^{3}$ \\ ${ }^{1}$ Department of Chemistry HVHP Institute of Post Graduate Studies and Research, Kadi, Gujarat, India \\ ${ }^{2}$ Department of Biotechnology, Pramukh Swami Science and H.D Patel Arts College, Kadi, Gujarat, India \\ ${ }^{3}$ Department of Chemistry, Arts, Science \& Commerce College, Pilvai, Gujarat, India
}

\begin{abstract}
Due to broad spectrum in physiologic diversity and their wide range of pharmacological activities, plants are playing an important factor for the pharmaceutical industry. Meswak tree is shrub and botanically known as Salvadora persica L. It has been used since ancient times as a chewing stick for oral hygiene. Many unique phytochemicals are naturally present in Miswak, which are described by traditional medicine as a remedy for various disease symptoms with beneficial properties. The biological active compounds that are present in plants are referred as phytochemicals. These phytochemicals are derived from different parts of plants such as leaves, barks, seed, seed coat, flowers, roots and pulps and thereby used as sources of direct medicinal agents. Phytochemistry describes the large number of secondary metabolic compounds present in the plants. The plants are the reservoirs of naturally occurring chemical compounds and of structurally diverse bioactive molecules. The extraction of bioactive compounds from the plants and their quantitative and qualitative estimation is important for exploration of new biomolecules to be used by pharmaceutical and agrochemical industry directly or can be used as a lead molecule to synthesize more potent molecules. This review includes the analytical methodologies in which extraction methods and the process of analysis for bioactive compounds present in the plant extracts through the different Aaalytical techniques like HPLC, GC, GC, OPLC etc. and the detection of compound by mean of FTIR, NMR, and MS.
\end{abstract}

KEY WORDS: SALVADORA, PHYTOCHEMISTRY, ANALYTICAL TECHNIQUES, MESWAK

\section{ARTICLE INFORMATION:}

Corresponding Authors: dbsikhwal@gmail.com

Received 15 ${ }^{\text {th }}$ Sep, 2018

Accepted after revision $21^{\text {st }}$ Dec, 2018

BBRC Print ISSN: 0974-6455

Online ISSN: 2321-4007 CODEN: USA BBRCBA Thomson Reuters ISI ESC / Clarivate Analytics USA

Mono of Clarivate Analytics and Crossref Indexed Journal Mono of CR

NAAS Journal Score 2018: 4.31 SJIF 2017: 4.196

( $)$ A Society of Science and Nature Publication, Bhopal India 2018. All rights reserved.

Online Contents Available at: http//www.bbrc.in/

DOI: $10.21786 / \mathrm{bbrc} / 11.4 / 26$ 


\section{INTRODUCTION}

Medicinal plants have been the keystone of traditional herbal medicine amongst occupant of rural area worldwide since old time. The therapeutic use of plants certainly goes back to the Sumerian and the Akkadian civilizations in about the third millennium BC. Hippocrates (ca. 460-377 BC), one of the ancient authors who described medicinal natural products of plant and animal origins, listed approximately 400 different plant species for medicinal purposes. According to the World Health Organization, a medicinal plant is the plant in which one or more of its organs, contains substances that can be used for therapeutic purposes, or which are precursors for chemo-pharmaceutical compounds. Medicinal plant will have chemical components that are medically active in its parts including leaves, roots, rhizomes, stems, barks, flowers, fruits, grains or seeds, which are employed in the control or treatment of a disease condition. These chemical compounds or bioactive components (non-nutritional) are often referred to as phytochemicals ('phyto-'from Greek - phyto meaning 'plant') or phytoconstituents and are responsible for protecting the plant against microbial infections or infestations by pests (Doughari, et al. 2009) In present medical world oral hygiene is one of the most important daily routine practices for keeping the mouth and teeth clean and prevents many health problems, (Halawany et al. 2012).

Recently, there have been considerable interest in exploring the medicinal properties of $S$. persica. Methanol, ethyl acetate, and diluted acetone extracts of $S$. persica were screened for in vitro activity against some Candida species with the extract of $J$. regia L. (Naumi et al. 2009) The $S$. persica plant contain different ingredient which are helpful in the treatment of osteoporosis, (Fouda et al. 2017). The aqueous extract of $S$. persica leaves possesses analgesic activity and decreases carrageenan-induced inflammation in rat paw, (Ramadan et al.2016). Another study has revealed that there are 5-0-caffeoylquinic acid and 4,5-0-Dcaffeoylquinic acid present as the major phenolic compounds in the root of $S$. persica while the stem is rich in 5-0-caffeoylquinic acid, 3,5-0-Dcaffeoylquinic acid, catechin, and epicatechin, (Aumeeruddya et al. 2017). A high content of 5-0-caffeoylquinic acid, naringenine, and some alkaloids, including caffeine, theobromine, and trigonelline was also reported from the bark. A new sulphur-containing imidazoline alkaloid, persicaline, along with five known compounds was identified in S. persica which have different phytochemical activities, (Mohamed Farag et al. 2018).

Several studies have probed into the biological profile of this plant and a wealth of literature has emerged and published. In this direction we aimed to explore the up to date data review regarding $S$. persica. On the basis of this background, therefore, the purpose of this piece of study is to provide baseline information of the effectiveness of $S$. persica stick extract in different aspects. The phytochemical bio-application of $S$. persica in various fields have also been systematically reviewed. Lastly, possible future directions of research and priority are also discussed.

\section{HISTORY}

According to ancient Greek and Roman literatures from the $3500 \mathrm{BC}$, the evolution of the toothbrush may be traced from chewing sticks that were used by Babylonians and to toothpicks that were chewed to help clean the teeth and mouth, (Wu et al. 2001). During the old days, the laws of Manu of ancient Vedic India stipulated that the teeth be cleaned as part of the daily hygienic rituals, (Hyson et al. 2003). This review includes the history and the use of "Meswak" as an oral tool, as well as the biological effects of $S$. persica extracts. Chewing sticks are considered the most popular among all of the dental care tools for their simplicity, availability, low cost and their traditional and/or religious value (Halawany et al. 2012, Riggs el at. 2012).

Medical books of ancient India, Susruta Samhita and Charaka Samhita, have also stressed on oral hygiene using herbal sticks, (Dahiya et al. 2012). There are various biological properties, including significant antibacterial, (Al-sieni et al. 2013, Rasouli et al. 2014) antifungal, (Almas et al 1999) and anti-plasmodial effects in the extract of miswak. During the 2nd century BC, the Greek sophist, Alciphron, recommended a toothpick to clean the "fibrous residue" that remained between the teeth after meals. The Greek word, karphos, Alciphron used to describe the toothpick, is roughly translated to 'blade of straw'. The Romans had also used toothpicks from the mastic tree (Pistacia lentiscus). The Gospel of Buddhism mentions Buddha receiving a "tooth stick from the god, Sakka". The Talmud mentions "quesem”, a splinter or wooden chip that was "divided at one end by chewing and biting" and used like a toothbrush.

\section{COMMON NAME}

Salvadora persica is commonly known as tooth brush tree but it does also have various names in different languages, in Arabic it is used to be called "Miswak" whereas in Hindi it is known a "Meswak" or "Pillu". The name of any plant varies as per the geographic areas. $S$. persica is well known plant in India and has many local names which include "Gudphala" in Sanskrit, "Uka" or "Ukaay" or "Oamai” in Tamil, "Gonimara”, "Kankhira" 
or "Genumar" in Kanada and "Gunnangi" in Telegu. In the western-northern area of India $S$. persica grows in large number. In Gujarat people know it as "Pilludi" or Pilu" or "Kharijal" whereas Rajasthani language has a name "Jaal" for it. In other languages it has venerable names, "Khabbar" in Sindhi, "Arak" in Assamese, "Peelu" in Punjabi, "Khakan" in Marathi. In Dutch it is known as "Zahnbürstenbaum”, "Misvak ağacı" in Turkish, "Kerriebos" in Namibia, "Asawaki, kighir" in Nigeria and "Chigombo" or "Iremito" or "Mkayo" in Tanzania.

\section{DESCRIPTION OF THE PLANT}

Traditionally rheumatism, leprosy, gonorrhoea, ulcers, scurvy, tumours and dental diseases can be treated from S. persica (Miswak) (Almas et al. 1995, Jindal et al. 1996). Dr. Laurent Garcin proposed the term Salvadora, (Juan Salvadory Bosca, 1598-1681) while as persica was oriented from Persia and L. is used to indicate Carl Linnaeus (1707-1778), the father of modern taxonomy. As a shrub the miswak pant has long branches, often pendulous or semiscandent, glabrous or pubescent and the leaves are sub succulent; blades coriaceous, landeolate to elliptic, occasionally orbicular, $1-3-10 \mathrm{~cm}$ long, $1-2-3 \mathrm{~cm}$ wide, rounded to acute at apex, cuneate to subcordate at base. Flowers are small, greenish-white with lateral and terminal panicles up to $10 \mathrm{~cm}$ long and petals up-to $3 \mathrm{~mm}$ long. Drupes red or dark red purple when ripe. (Malik S et al. 1987) Besides its medicinal potentialities, it is also suitable in agroforestry systems as a wind break and helps in land reclamation (Gururaja GR et al. 2004, Bhatia B et al. 2000). The ripe fruits of this tree are sweet and edible (locally called as Piloo) and consumed by rural/tribal population. The seeds of Salvadora yield a pale-yellow solid fat, rich in lauric and myristic acid content which is used in making soaps, illuminants, varnishes, paints as well as in food industry. It is recognized as nonconventional oil seed tree crop.

\section{TAXONOMIC POSITION}

The genus Salvadora belongs to family 'salvadoraeceae'. It comprises three genera (i.e. Azima, Dobera and Salvadora) and 10 species distributed mainly in the tropical and subtropical region of Africa and Asia. It belongs to 'Magnoliophyta' division which is further classified in different classes in which Salvadora belong to 'Magnoliopsida'. The order of plant is 'Brassicales'.

\section{USE AND PHYTOCHEMICALS}

In Middle Eastern, some Asian and African cultures chewing sticks are prepared from the roots and twigs of $S$. persica. To prepare this type of sticks the stings or roots are cut into pieces of $10-$ to $25-\mathrm{cm}$ long. The sticks of Miswak can usually be used 3-10 times daily considered as an inexpensive and an efficient oral hygiene. (AI-Bagieh NH et al. 1988) The Primary Health Care Approach (PHCA) principles entirely consider the use of Miswak. (Hyson JM el at. 2003) The use of chewing sticks as an oral hygiene tool like Miswak, where it is traditionally grown is encouraged and recommended by the World Health Organization (WHO). (WHO et al. 1987) In addition Miswak is also recommended for the teeth whitening, the memory improving tool, the breath freshener, calming the bile, drying up the phlegm, the gums strengthening, sharpening the vision and increasing the appetite, (Almas et al. 2001). Antimicrobial substances such as sulfur can be extracted from its roots and stems, moreover Trimethylamine, benzyl isothiocyanate, Salvadorine, beta cholesterol, tannins, saponines, sodium chloride, potassium chloride, vitamin C, flavonoids and sterols are associated with anti-bacterial effects. Besides this, the significant amounts of added silica can help to remove plaque mechanically, (Almas et al.1995). In this plant fluoride is also found in measurable quantities, (Darout et al. 2000) which is easily dissolved and released in water.

\section{MATERIALS AND METHODS}

\section{PROCEDURE FOR SEARCHING INFORMATION}

Relevant literature survey was done by scientific websites and tabs i.e Google Scholar, Scientific journal. Information was also obtained from books and e-articles. The scientific name of the plant was validated using The Plant List. Published review papers on S. persica were used as guidelines to design the present study and also to add missing data to ensure a more comprehensive and up-to-date review is obtained. The reference lists of review and research papers were searched for further relevant information. Regarding the search methodology, the following keywords were searched: "Salvadora persica plant extraction", (Google $=68,300$ search results, Articles $=4,640$ ).

\section{PLANNING, DESIGN AND DESCRIPTION OF SECTIONS}

This review consists of different nine Sections covering the traditional uses, phytochemistry, pharmacological properties, and bio-applications of S. persica. The third subsection of seventh section highlights about the extraction and separation of bioactive compounds of Miswak plant. Section 8 and 9 include the separation of phytochemicals in $S$. persica plant through different extraction methods. The sections reviewed about the phytochemicals and bioactivity of different compounds 
from the plant extract. The detailed antimicrobial activity of $S$. persica has been displayed in the section 10 , lastly, section 11 provides an overview of the potential applications of $S$. persica in various fields.

\section{PLANT MATERIAL}

First the fresh plant/plant parts can be collected randomly from the semi-arid or xerophytic region. The sticks of plant are dried at $55^{\circ} \mathrm{C}$ by use of an oven for three to four days and then cut into slices then ground into a fine powder using a mixture grinder. The extract of plant Miswak can be prepared by adding $40 \mathrm{~g}$ of the Miswak powder to $200 \mathrm{ml}$ of solvent in which water, ethanol and hexane are preferred, in a closed container and stored at room temperature for $48 \mathrm{~h}$. The solvents are then filtrated through a Whatman No. 1 filter paper and allowed to evaporate at $40^{\circ} \mathrm{C}$ in an oven for $72 \mathrm{~h}$. The dried extracts are considered 100\% pure and used to prepare different concentrations by adding the same solvents in an amount of 100, 250 and $500 \mathrm{~g} / \mathrm{ml}$. different commercial toothpaste brands can be used to control for all of the antimicrobial tests by making the concentration of $100 \mathrm{~g} / \mathrm{ml}$ by allowing to dry and ground. 250 $\mathrm{mg}$ of dried extract is dissolved to prepare the Miswak mouth wash by using of $1 \mathrm{~L}$ of distilled water. (Mohammad Abhary et al. 2016)

As scrutinizing the aimed review article, it is observed that after the collection of plant extraction is carried out by different methods according to the nature of phytochemical which are present in plant. As the review on Miswak, some common method of extraction includes cold extraction and solvent extraction using Soxhlet apparatus. At present a common Universal Extraction System (Buchi) is used for the purpose of extraction.

\section{PLANT EXTRACTION}

\section{Cold extraction method}

It is reviewed that several of extraction is done by this method because of low costing and high productivity with efficiency. During the process of cold extraction, Measurable weight of dried powder is taken and respective solvents is added into conical flask then allow at room temperature for thirty-minute then after it is kept for seven days and during this period shaking is allowed after each twenty-four hours for seven days. Finally filter the extract through Whatman filter paper under vacuum and dry it at room temperature in watch glass dish. Note down the weight of each dish prior to drying of the extracts and after drying too. The difference was calculated by the weight of the extract. (Harborne et al. 1973).

\section{Solvent extraction method}

Recently the Universal Extraction System (Buchi) is used for solvent extraction. First the dried plant powder taken various parts placed in glass thimble for extraction purpose with the use of various solvents. For each extract the procedures are carried out for 10 cycles, and the temperature is adjusted just below the boiling point of the respective solvents. The resulting solvent extract is filtered, concentrated in vacuum concentrator and used to determine the presence of phyto constituents (Harborne et al. 1973)

\section{Supercritical fluid extraction (SFE)}

Supercritical fluid chromatography (SFC) provides a useful alternative to gas chromatography and liquid chromatography for some plant samples which involves use of gases as mobile phase at a temperature and pressure exceeding its critical point, usually $\mathrm{CO}_{2}$ is used and compressing them into a dense liquid under these conditions the mobile phase is neither a gas nor a liquid. The turbid liquid is then pumped through a cylinder containing the material which to be extracted. From there, the extract- hampered liquid is pumped into a separation chamber where the extract is separated from the gas and the gas is recovered for re-use. $\mathrm{CO}_{2}$ is commonly used because its low critical temperature, $31^{\circ} \mathrm{C}$, and critical pressure, $72.9 \mathrm{~atm}$, are relatively easy to achieve and maintain. Solvent properties of $\mathrm{CO}_{2}$ can be manipulated and adjusted by varying the pressure and temperature. The advantages of SFE are, no solvent residues left in it as $\mathrm{CO}_{2}$ evaporates completely, (Patil et al. 2010).

\section{Microwave-assisted extraction (MAE)}

The combination of microwave and traditional solvent extraction is simply termed as microwave extraction. Microwave-assisted extraction is considered as the heating of solvents and plant tissue using microwave which increases the kinetic of extraction (Delazar et al 2012). To remove the minute microscopic traces of moisture present in plant cell, the extraction is heated in dried plant material. As a result of the heating up of this moisture inside the plant cell due the evaporation of moisture occurs and generates tremendous pressure on the cell wall. Due to the pressure the cell wall is pushed from inside and the cell wall ruptures. Thus, from the ruptured cells the exudation of active constituents occurs, hence increasing the yield of phytoconstituents, (Gordy et al. 1953 and Goldman et al. 1963).

\section{IDENTIFICATION OF PHYTOCHEMICALS}

The separation of bioactive compound which are present in the plant extract with different polarities is a challenging task for the process of identification and charac- 
Sharma, Shah and Dave

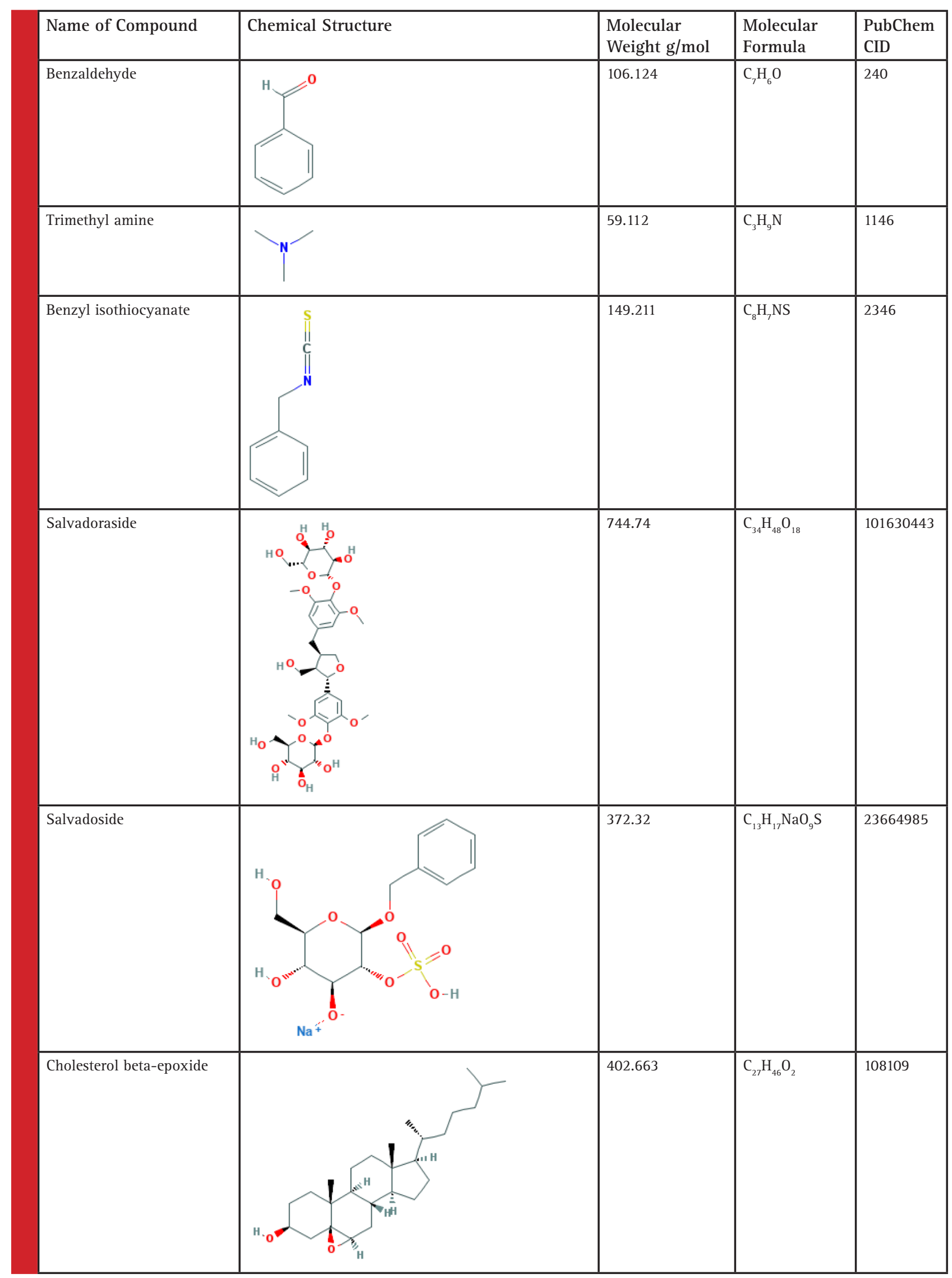

738 
Sharma, Shah and Dave

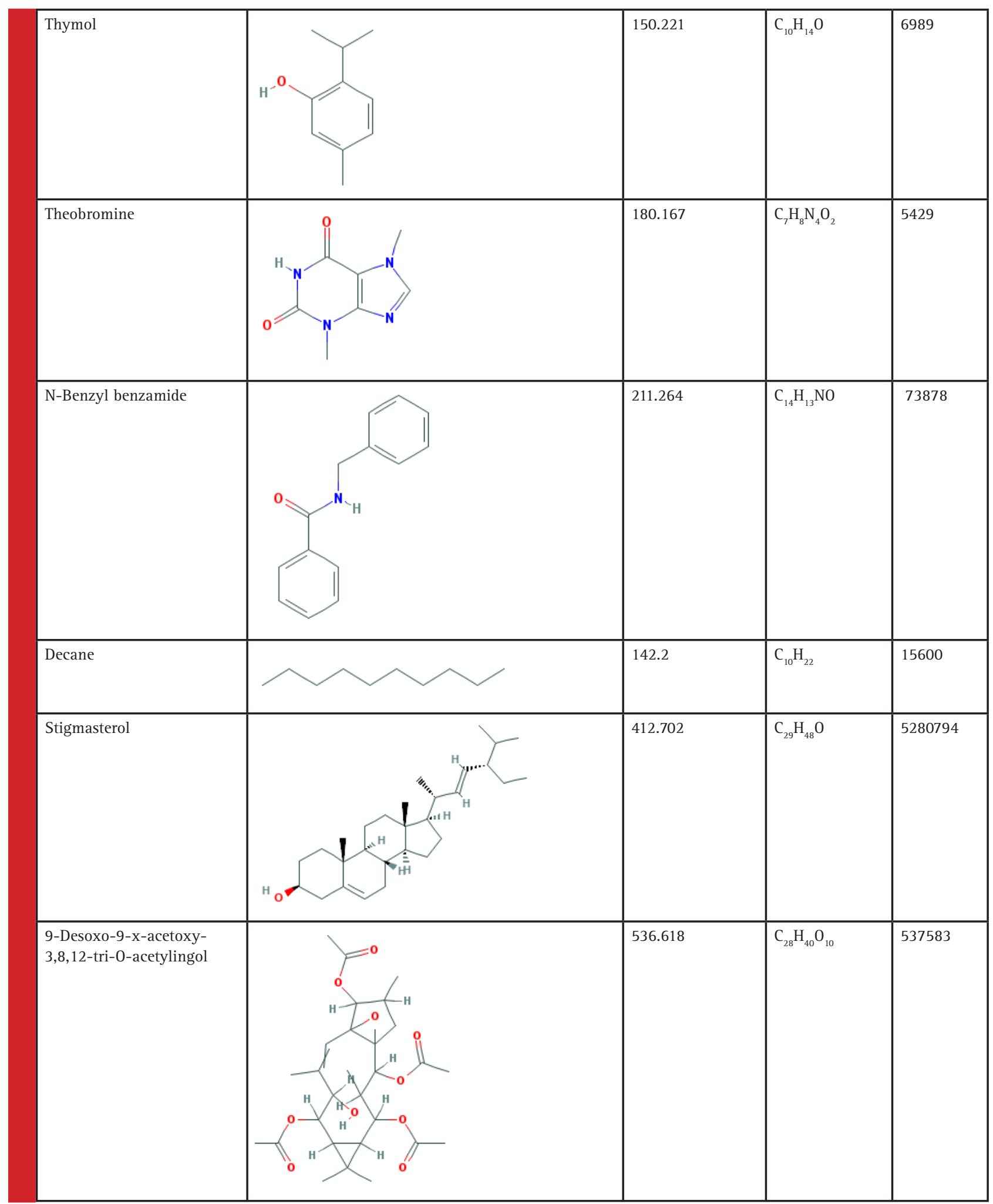




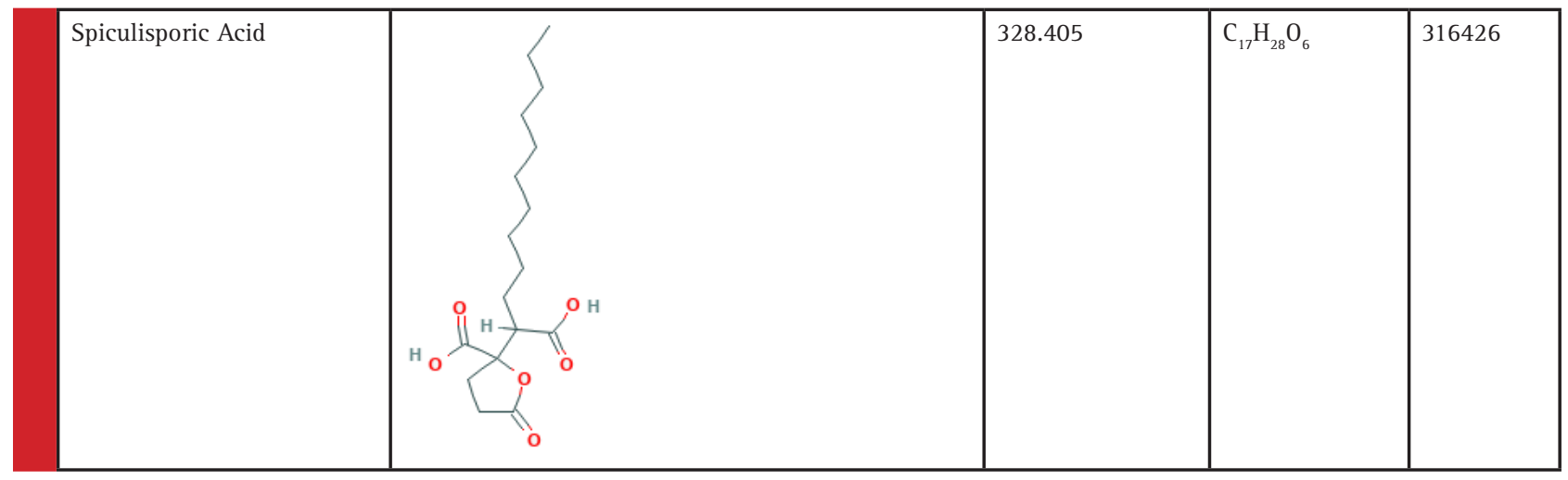

terization of bioactive compounds. It is a common practice to use TLC, HPTLC, paper chromatography, column chromatography, Gas chromatography, OPLC and HPLC, should be used to obtain pure compounds in isolation of bioactive compounds. The pure compounds are then used for the determination of structure and biological activity, (Sasidharan et al. 2011).

\section{Physicochemical and Phytochemical Studies}

Phytochemical studies include extractive values, total ash, acid insoluble ash, total sugar, starch, tannin, and phenols can be calculated from the shade-dried and powdered (60 mesh) plant material. (Peach K et al. 1955, Ayurvedic Pharmacopeoeia of India. Part I et al. 2001, 2004). The Antioxidant Activity of the plant extracts and standard was assessed on the basis of the radical scavenging effect of the stable DPPH (2,2-diphenyl-1picryl-hydrazyl-hydrate) free radical. (Verma et al 2012, Gupta et al. 2015).

Methanol was used to make working solutions of the test extracts. Ascorbic acid was used as the standard in solutions ranging from 1 to $50 \mu \mathrm{g} / \mathrm{ml}$. In methanol $0.002 \%$ DPPH solution is prepared. Then $2 \mathrm{ml}$ of this solution was mixed with $2 \mathrm{ml}$ of sample solutions (ranging from $25 \mu \mathrm{g} / \mathrm{ml}$ to $500 \mu \mathrm{g} / \mathrm{ml}$ ) and the standard solution to be tested separately. These solution mixtures were kept in the dark for 30 min and optical density was measured at $517 \mathrm{~nm}$ using a Shimadzu spectrophotometer against methanol. The blank used was $2 \mathrm{ml}$ of methanol with $2 \mathrm{ml}$ of DPPH solution (0.002\%). The optical density was recorded and percentage of inhibition was calculated using the equation: \% of inhibition of DPPH activity $=(\mathrm{A}-\mathrm{B}) / \mathrm{A} \times 100$; where $\mathrm{A}$ is optical density of the blank and $B$ is optical density of the sample.

\section{HPTLC STUDIES}

Air dried $\left(45-55^{\circ} \mathrm{C}\right)$ powdered stem and twig of $S$. persica $(2.0 \mathrm{~g})$ in triplicate were extracted separately with 3 X 20 $\mathrm{ml}$ methanol. Extracts were concentrated under vacuum and re dissolved in methanol, filtered and finally made up to $100 \mathrm{ml}$ with methanol prior to HPTLC analysis. Reagents used were from Merck (Germany) and standard ferulic acid was procured from Sigma-Aldrich (Steinheim), (Verma et al 2012, Gupta A et al. 2015).

\section{Antimicrobial effects}

Different antimicrobial activity was performed which can An in vitro study showed that the aqueous extract of $S$. persica miswak had an inhibitory effect on the growth of Candida albicans that may be attributed to its high sulfate content (al-Bagieh, N. et al. 1995). Some studies investigated the derivatives of $S$. persica miswak using three different laboratory methods, and demonstrated strong antimicrobial effects on the growth of Streptococcus sp. and Staphylococcus aureus. (Al Lafi, et al. 1995) In addition, some showed that Enterococcus faecalis is the most sensitive microorganism affected by the use of $S$. persica miswak, and noted no significant difference in the antimicrobial effects of freshly cut and 1-month-old miswak. A comparison of the alcoholic and aqueous extracts of $S$. persica miswak revealed that the alcoholic extract had more potent antimicrobial activity than did the aqueous extract (Al-Bagieh, et al. 1997).

Aqueous extract of plant inhibited all the microorganisms, showing greater activity on Streptococcus species. Methanolic extract was resisted by L. acidophilus and $P$. aeruginosa. At highest concentration tested (200 $\mathrm{mg} / \mathrm{ml}$ ), the aqueous extract was more efficient than the methanolic extract but were less efficient than the positive control streptomycin and amphotericin B. (Al-Bayati et al. 2008) Miswak extract displayed greater reduction in both S. mutans and Lactobacillus cariogenic bacteria counts. Reduction of microbial count in females was more for both microorganisms as compared to males, (Bhat et al. 2012). Ethanol extract was more effective than the aqueous extract in inhibiting the $S$. mutans, $L$. acidophilus, E. coli, S. aureus, and P. aeruginosa microorganisms. The aqueous extract did not display any inhibitory effect on $P$. aeruginosa. (Mohammed, et al. 
2013). The miswak extracts showed comparable or slightly stronger activity compared to some toothpastes. The aqueous extract exhibit antibacterial activity on $M$. bovis (Fallah et al., 2015).

All solvent-extracts inhibited the $S$. aureus, $S$. mutans, S. sanguinis, S. sobrinus, S. salivarius, L. acidophilus microorganisms. Methanol extract was more effective than the other extracts. (Kumar et al., 2016) $S$. persica aqueous extract showed higher activity than methanol extract against $S$. aureus while the opposite effect was observed against $E$. coli. Compared to $C$. mopane and $D$. cinerea, $S$. persica was most effective against $S$. aureus but was least effective against $E$. coli, (Mudzengi et al., 2017).

\section{CONCLUSION}

Our literature review concludes that the use of $S$. persica miswak as an oral hygiene aid is effective. Descriptive and experimental studies have provided considerable evidence that the $S$. persica plant and its extracts exert beneficial effects on the oral tissues and help to maintain good oral hygiene. It is encouraging to note the large number of studies and clinical trials that have examined the effects of $S$. persica miswak and the value that people have attached to it since ancient times. The use of $S$. persica miswak alone or in combination with conventional toothbrushes, when performed judiciously, will result in superior oral health and hygiene. It is to be noted that there had been earlier attempts to summaries the medicinal potential of $S$. persica, even though with a different or a less broad ethnopharmacological focus. However, this review can be considered as the first attempt to broaden and critically assess scientific evidence on the ethnopharmacology of $S$. persica. It is obvious from this review that $S$. persica can be regarded as an important traditionally used medicinal plant harboring a panoply of bioactive compounds, pharmacological properties, and modern applications in emerging fields of interest. It is anticipated that this review article will open new avenues for research and stimulate further studies that will fill research gaps highlighted above.

\section{REFERENCES}

Abdel-Motaal Foudaa, Amany Ragab Youssef (2017) Antiosteoporotic activity of Salvadora persica sticks extract in an estrogen deficient model of osteoporosis. Osteoporosis and Sarcopenia, Volume-3, 132-137

Almas K. (2001) The effect of extract of chewing sticks (Salvadora persica) on healthy and periodontal involved human dentin A SEM study. Indian J Dent Res 12:127-132.
Al-Bayati, F.A., Sulaiman, K.D. (2008) In vitro antimicrobial activity of Salvadora persica L. extracts against some isolated oral pathogens in Iraq. Turk. J. Biol. 32 (1), 57-62.

AI-Bagieh NH, Weinberg ED. (1988) Benzylisothiocyanate: a possible agent for controlling dental caries. Microbios Lett 39:143-51.

Al-Bagieh, N., Almas, K. (1997) In vitro antibacterial effects of aqueous and alcohol extracts of miswak (chewing sticks). Cairo Dent. J. 13, 221-224

Al-Bagieh, N., Idowu, A., Salako, N.O. (1994). Effect of aqueous extract of miswak on the in vitro growth of Candida albicans. Microbios 80 (323), 107-113.

Al-sieni AI. (2013) The antibacterial activity of traditionally used Salvadora persica L. (miswak) and Commiphora gileadensis (palsam) in Saudi Arabia. Afr J Tradit Complement Altern Med. 11(1): 23-7.

Almas K, AI-Bagieh NH (1999) The antimicrobial effects of bark and pulp extracts of meswak Salvadora persica Biomed Lett 60:71-5.

Almas K, Al-Lafi TR. (1995) The natural toothbrush. World Health Forum 16:206-210.

Al Lafi, T., Ababneh, H. (1995) The effect of the extract of the miswak (chewing sticks) used in Jordan and the Middle East on oral bacteria. Int. Dent. J. 45, 218-222.

Anonymous (2007) Ayurvedic Pharmacopeoeia of India. Part I, Vol I. Department of Health, Ministry of Health and Family Welfare, Government of India, New Delhi; 2004. p. 152165.

Anonymous (2007a) Indian pharmacopoeia, Government of India, Ministry of Health and Family Welfare, Controller of Publications, New Delhi; 2007. p. 191.

Anonymous (1984) Official methods of Analysis (AOAC), 4th edn. Association of Official Chemists, Inc. U.S.A; 1984. p. 1878.

Anonymous. (1972) The wealth of India - Raw materials (New Delhi, CSIR), 1972; 9: 193-195.

Aumeeruddya, M.Z.; Zenginb, G.; Mahomoodally, M.F. A review of the traditional and modern uses of Salvadora persica L. (Miswak): Toothbrush tree of Prophet Muhammad. J. Ethnopharm. 2017, 213, 409-444.

Bhat, P.K., Kumar, A., Sarkar, S., (2012) Assessment of immediate antimicrobial effect of miswak extract and toothbrush on cariogenic bacteria-A clinical study. J. Adv. Oral. Res. 3 (1) 13-18.

Bhatia B, Sharma HL (2000) Fuelwood production and wasteland reclamation, Botanica 2000; 14: 84-93.

Dahiya P, Kamal R, Luthra RP, Mishra R, Saini G. (2012) Miswak: a periodontist's perspective. J Ayurveda Integr Med 3(4):184-7.

Darout IA, Christy AA, Nils Skaug, Egeberg PK. (2000) Identification and quantification of some potentially antimicrobial anionic components in miswak extract. Indian J Pharmacol. 32: 11-14. 
Delazar A, Nahar L, Hamedeyazdan S, Sarker SD. (2012) Microwave-assisted extraction in natural products isolation. Methods Mol Biol. 864:89-115

Doughari, J.H.; Human, I.S, Bennade, S. \&t Ndakidemi, P.A. (2009). Phytochemicals as chemotherapeutic agents and antioxidants: Possible solution to the control of antibiotic resistant verocytotoxin producing bacteria. Journal of Medicinal Plants Research. 3(11): 839-848.

E. Noumi, M. Snoussi, H. Hajlaoui, E. Valentin, A. Bakhrouf., (2009). Antifungal properties of Salvadora persica and Juglans regia L. extracts against oral Candida strains. European Journal of Clinical Microbiology Et Infectious Diseases,

E. Riggs, C. van Gemert, M. Gussy, E. Waters, N. Kilpatrick (2012) Reflections on cultural diversity of oral health promotion and prevention, Global Health Promot. 19 (1) 60-63, http://dx.doi.org/10.1177/1757975911429872.

Fallah, M., Fallah, F., Kamalinejad, M., Malekan, M.A., Akhlaghi, Z., Esmaeili, M., (2015). The antimicrobial effect of aquatic extract of Salvadora persica on Mycobacterium bovis in vitro. Int. J. Mycobacteriology 4, 167-168.

Goldman R. (1962) Ultrasonic Technology. Van Nostrand Reinhold, New York. 1962.

Gordy WWV, Smith RF Trambarulo. (1953) Microwave Spectroscopy. Wiley, New York. 1953.

Gupta A, Verma A, Kushwaha P, Srivastava S, Rawat AKS. (2015) Phytochemical and Antioxidant Studies of Salvadora persica L. Stem \& Twig. Indian Journal of Pharmaceutical Education and Research | Vol 49 | Issue 1 | Jan-Mar, 2015

Gururaja GR, Nayak AK, Chinchmalatpure AR, Nath A, Babu VP. (2004) Growth and Yield of Salvadora persica, A facultative halophyte grown on saline black soil (Vertic Haplustept), Arid Land Research and Management 18(1): 165168.

Harborne JB. (1973) Phytochemical methods. Chapman and Hall Ltd., London. 49-88

H. Ahmad, K. Rajagopal, Biological activities of Salvadora persica L. (Meswak), Med. Aromat. Plants 2 (4) (2013), http:// dx.doi.org/10.4172/21670412.1000129.

H.S. Halawany (2012) A review on Miswak (Salvadora persica) and its effect on various aspects of oral health, Saudi Dent. J. 24 (2012) 63-69.

Hyson JM. (2003) History of the toothbrush. J Hist Dent 51(2):73-80.

Jindal SK, Bhansali R, Satyavir R. (1996) Salvadora tree - A potential source of non-edible oil, In: Proc of All India seminar on rabi oil seed crop (Jodhpur, CAZRI); 1996

Kumari, A., Parida, A.K., Rangani, J., Panda, A., (2017). Antioxidant activities, metabolic profiling, proximate analysis, mineral nutrient composition of Salvadora persica fruit unravel a potential functional food and a natural source of pharmaceuticals. Front. Pharmacol. 8 (61). http://dx.doi.org/10.3389/ fphar.2017.00061.
Malik S, Ahmed SS, Haider SI, Muzaffer A. (1987) Salvadoricine - a new indole alkaloid from the leaves of Salvadora persica, Tetrahedron Lett 28: 163-164.

Mohammad Abhary, Abdul-Aziz Al-Hazmi. (2016) Antibacterial activity of Miswak (Salvadora persica L.) extracts on oral hygiene. Journal of Taibah University for Science 10 513-520

Mohammed, S.G., (2013). Comparative study of in vitro antibacterial activity of miswak extracts and different toothpastes. Am. J. Agric. Biol. Sci. 8 (1), 82-88.

Mohamed Farag, Wael M. Abdel-Mageed, Omer Basudan and Ali El-Gamal, (2018), Persicaline, A New Antioxidant SulphurContaining Imidazoline Alkaloid from Salvadora persica Roots, Molecules 23, 483; doi:10.3390/molecules2302048

Mudzengi, C.P., Murwira, A., Tivapasi, M., Murungweni, C., Burumu, J.V., Halimani, T., (2017). Antibacterial activity of aqueous and methanol extracts of selected species used in livestock health management. Pharm. Biol. 55 (1), 1054-1060.

Noumi E, Snoussi M, Hajlaoui H, Valentin E, Bakhrouf A (2010) Antifungal properties of Salvadora persica and Juglans regia L. extracts against oral Candida strains. Eur J Clin Microbiol Infect Dis 29: 81-88.

Patil PS, Shettigar R.(2010) An advancement of analytical techniques in herbal research J Adv Sci Res. 1(1):08-14.

Peach K,Tracy MV.(1955) Modern Methods of Plant Analysis. Vol III and IV Springer, Heidelberg p. 258-61.

Ramadan, K.S., Alshamrani, S.A., (2016.) Phytochemical analysis and antioxidant activity of Salvadora persica extracts. J. Basic Appl. Res.2, 390-395

Rasouli GAA, Rezaei A, Hosein MSS, Yaghoobee S, Khorsand A, Kadkhoda Z, (2014) et al. Inhibitory activity of Salvadora persica extracts against oral bacterial strains associated with periodontitis: An in-vitro study. Journal of Oral Biology and cranio facial research 4: 19-23.

Sasidharan S, Chen Y, Saravanan D, Sundram KM, Yoga Latha L.(2011) Extraction, isolation and characterization of bioactive compounds from plants' extracts. Afr J Tradit Complement Altern Med. 2011; 8(1):1-10.

S. Dutta, A. Shaikh (2012) The active chemical constituent and biological activity of Salvadora persica (Miswak), Int. J. Curr. Pharmaceut. Rev. Res. 3 (1) ISSN: 0976-822X.

Verma S, Gupta A, Kushwaha P, Khare V, Srivastava S, Rawat AKS. (2012)Phytochemical Evaluation and Antioxidant Study of Jatropha curcas Seeds. Pharmcog J. 4(29): 5-54.

WHO (1987) Preventive methods and programmes for oral diseases. World Health Organization. Technical Report Series 713, Geneva; 1987.

Wolf W. (1966) A history of personal hygiene - customs, methods and instruments - yesterday, today, tomorrow. Bull Hist Dent 14(4):54-66.

Wu, C., Darout, I., Skaug, N. (2001). Chewing sticks: timeless natural toothbrushes for oral cleansing. J. Periodontal. Res. 36 (5), 275-284 